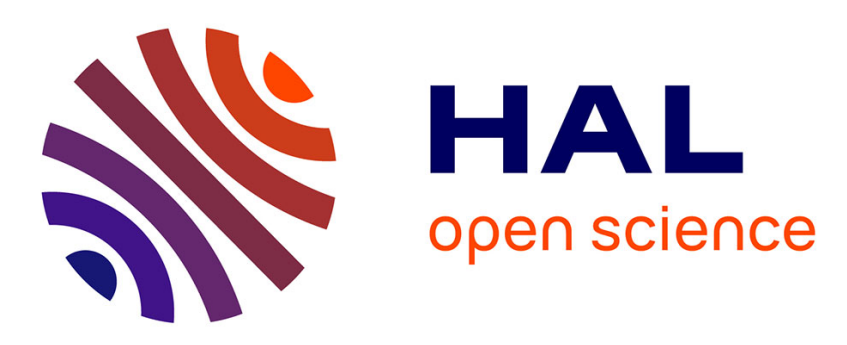

\title{
Evaluation of UWB communication for in-flight entertainment system in the aircraft cabin
}

Roxana Albu, Aubin Lecointre, Daniela Dragomirescu, Thierry Gayraud, Pascal Berthou

\section{> To cite this version:}

Roxana Albu, Aubin Lecointre, Daniela Dragomirescu, Thierry Gayraud, Pascal Berthou. Evaluation of UWB communication for in-flight entertainment system in the aircraft cabin. 7th IFAC International Conference on Fieldbuses and nETworks in industrial and embedded systems, November 7-8-9, 2007, Nov 2007, Toulouse, France. p. 49-56. hal-00356854

\section{HAL Id: hal-00356854 https://hal.science/hal-00356854}

Submitted on 28 Jan 2009

HAL is a multi-disciplinary open access archive for the deposit and dissemination of scientific research documents, whether they are published or not. The documents may come from teaching and research institutions in France or abroad, or from public or private research centers.
L'archive ouverte pluridisciplinaire HAL, est destinée au dépôt et à la diffusion de documents scientifiques de niveau recherche, publiés ou non, émanant des établissements d'enseignement et de recherche français ou étrangers, des laboratoires publics ou privés. 


\title{
EVALUATION OF UWB COMNUNICATION FOR IFE SYSTEM IN THE AIRCRAFT CABINE
}

\author{
Roxana Albu, Aubin Lecointre, Daniela Dragomirescu, \\ Thierry Gayraud and Pascal Berthou \\ LAAS-CNRS, University of Toulouse, Toulouse, France \\ Toulouse University of Science \\ INSA Toulouse
}

\begin{abstract}
This paper deals with the embedded network dedicated to the entertainment system of passenger cabin in an aircraft. The work described in this paper focuses on a wireless solution to interconnect the main components of this system. The selected solution is UWB with smart antennas. This solution is proved to be able to provide the system with the needed bandwidth. The self-configuration capability of the system is also demonstrated.
\end{abstract}

Keywords: embedded network, UWB, smart antennas, self configuration network, and IFE system.

\section{INTRODUCTION}

\section{THE DESCRIPTION OF IFE SYSTEM}

The objective is to take advantage of emerging wireless access media and availability of new passenger's devices to develop an innovative yet practical entertainment service concept based on customised content and information. This should lead to reconsider today's IFE () architecture and to envisage a new architecture based on wireless communication means covering PAX (Passenger) needs.

In this work package, a comprehensive analysis will be carried out on communication technologies in order to select the best solutions for on-board applications in the near future.

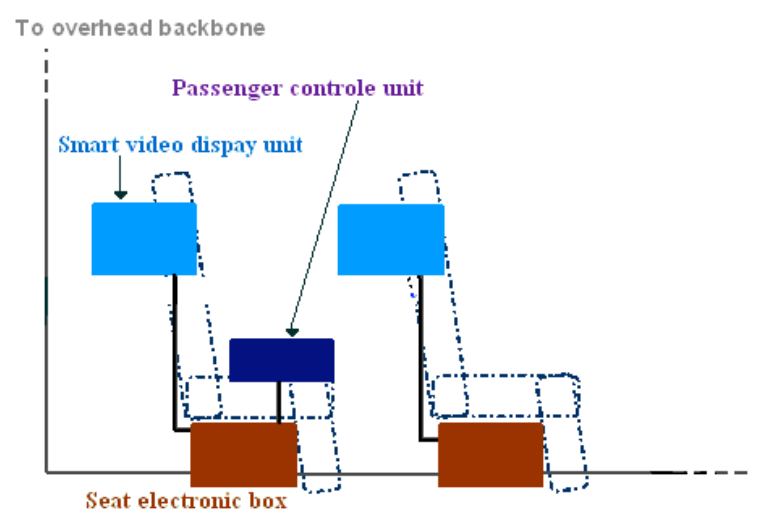

Fig. 1 Passenger Area Network (PAN)
The new IFE architecture has to provide a lot of entertainment services to PAX. But this new services have to be compliant with airlines constraints such as minimum system weight or reduce installation burden.

This part of the network is the one really near to the passenger. Its purpose is to permit the communication between various elements present in the PAX's seat and to insert these elements in the global IFE system.

- Seat Electronic Box: it's the interface between the IFE network and a small group of PAX's seats. On the PAX side, a Seat Electronic Box can connect 3 seats to the IFE network. This element also provides power to the in-seat equipments and so integrates a voltage transformer. It is directly connected to display units. When remote power outlets exist on the passenger's seat the Seat Electronic Box is divided into two separated boxes: one specialized for power and one dedicated to data.

- Smart Video Display Unit: this unit is the screen placed in the back of the seat in front of the PAX and which allows him to interact with the IFE system. It can also be arm mounted in case of no seat are present in front of the one of the PAX. This element can be a touch screen one and usually goes with the Passenger Control Unit.

- Passenger Control Unit: this unit is composed of a remote control to interact with the system and an audio jack 
connector to plug headphones for listening audio contents. The Passenger Control Unit has to communicate with Smart Video Display Unit in front of it but these two equipments are not connected to the same Seat Electronic Box. In this case, link that exists between two Seats Electronics Boxes is used.

Actually the objective is to suppress every specific data wire between these two units (of course power lines are preserved).

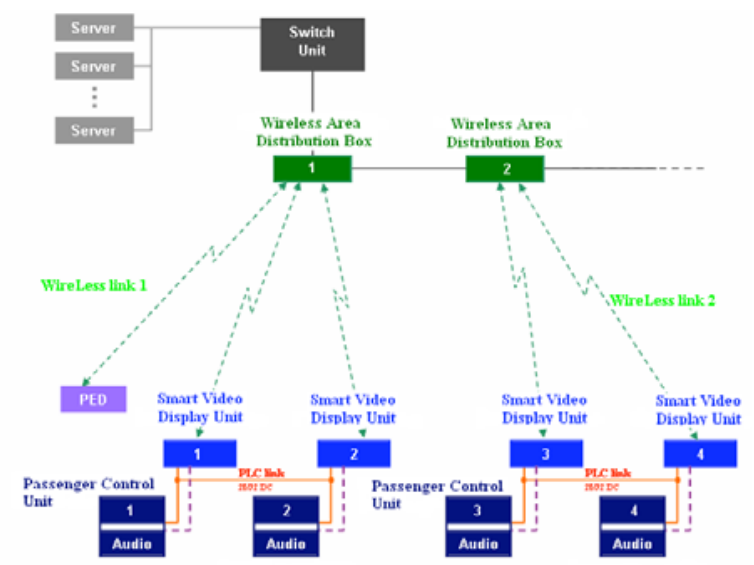

Fig. 2 Architecture for IFE system

\subsection{System and installation constraints}

Commercial aircrafts come in different models (single aisle, long range). And each airline has special needs for the size of the first class / business class / economy classes and special areas.

The IFE system should be adaptable to each possible layout. Ideally the same base system should be usable on small and large aircraft types.

For example a layout for a long-range aircraft is shown:

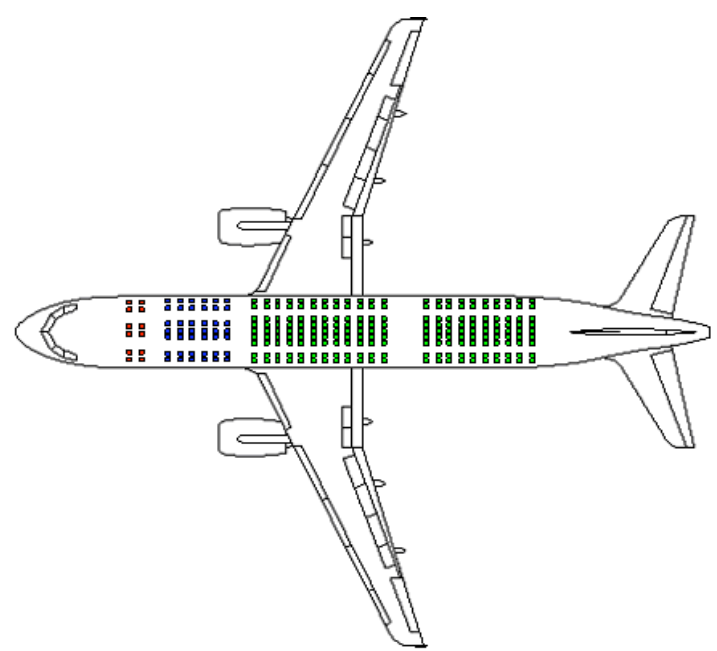

Fig. 3 Typical seat layout with 252 seats
To minimize customisation costs the flexibility must not induce complete cabling engineering for each customer.

\subsection{Environmental constraints (temperature, vibration, EMC...)}

To give business jet passenger best comfort in cabin, noise reduction is a permanent preoccupation for designers. Noise and seat parasite vibrations (due for example to entertainment equipment cooling fans ...) must be minimised.

Main constraints are:

- $\quad$ On line temperature from $-20^{\circ} \mathrm{C}$ to $+55^{\circ} \mathrm{C}$;

- Max acceleration 6g/ 6 axes.

\subsection{Weight and power consumption}

Depending on the large number of seats in a longrange aircraft with 300 seats every gram in seatequipment counts as 300 gram for the aircraft. Counting all electronics and installation material belonging to the IFE system up to 2 tons can be reached.

A very rough and very wrong number would be saying each gram will cost a dollar in fuel consumption per year, but it might be a handy picture.

Similar it is for power. As a rule of thumb it can be kept in mind that the entertainment electronics for a seat consume around $30 \mathrm{~W}$ atts.

The power consumption shall be minimized and shall not exceed 80 Ampere in 12 seats configuration with all onboard devices at their maximum electric consumption.

\section{TRANSMISSION \& INTEFERENCE STUDY}

As we have seen, the problematic consist in designing a radio layer for this specific context. That is to say entertainment (video \& audio) indoor communications for a large number of nodes. This implies that we have to define a solution enabling the communication for each user at the specified constraints (especially the data rate). As a result we have to deal with the interference problem for assuring the cohabitation of a large number of communications in the aircraft.

\subsection{The Proposed Solution}

We have chosen to study Impulse Radio Ultra WideBand (IR-UWB) as radio layer core for distinct reasons which come from the IR-UWB 
concept. IR-UWB is defined as a wireless radio which uses more than $500 \mathrm{MHz}$ of $10 \mathrm{~dB}$ bandwidth (Oppermann, et al. 2004). It provides solution for WPAN (Wireless Personal Area Network). IR-UWB profits from this very large bandwidth for using very short impulse (<10 ns) in order to send information (Oppermann, et al. 2004). This concept is the pulse modulation. That is to say that we encode the data to send in the pulse. While figure 4 illustrates different waveforms of pulse and theirs spectra, the figure 5 exposes different pulse modulations.

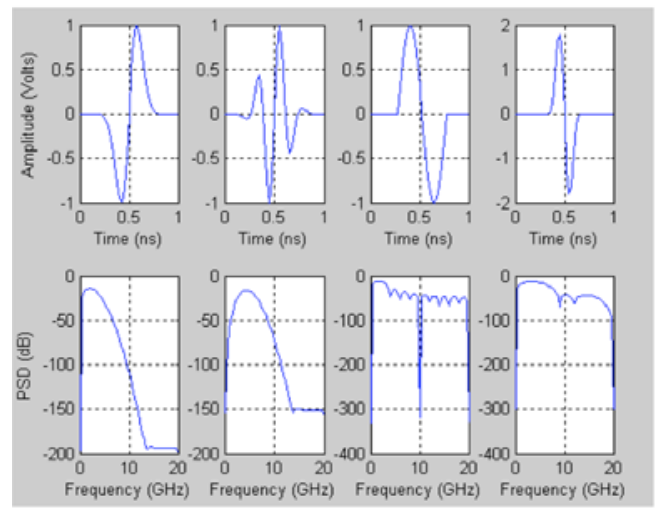

Fig 4. UWB pulse waveform.

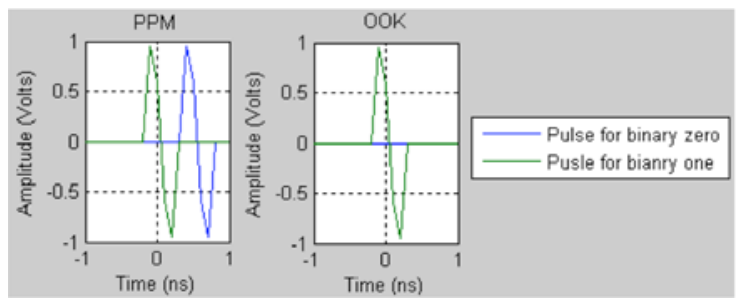

Fig 5. IR-UWB modulation.

Thanks to the figure 5, we can explain, for example, the principle of PPM (Pulse Position Modulation) and the OOK Modulation (On Off Keying) (Oppermann, et al. 2004). The OOK consist in sending a pulse for representing a binary one, while a binary zero is representing by an absence of impulsion. PPM used a delay for differentiating the pulse representing the binary from the binary zero pulse. That is to say that between two distinct pulses we will have a delay.

Figure 6 illustrates the emission of the following flow of binary data in PPM and OOK modulation:'100101011'.
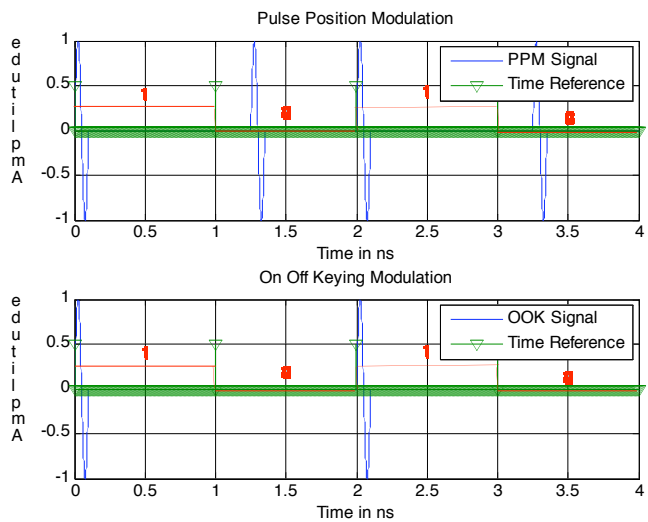

Fig 6 - PPM and OOK modulation for transmitting "1010"

\subsection{Why IR-UWB}

UWB (Barret, 2000) radio transmissions can legally operate in the range from $3.1 \mathrm{GHz}$ up to $10.6 \mathrm{GHz}$, at a limited transmit power of $-41 \mathrm{dBm} / \mathrm{MHz}$. Consequently, UWB provides dramatic channel capacity at short range that limits interference.

IR-UWB has some advantages such as: $7,5 \mathrm{GHz}$ of free spectrum which could permit to reach high data rate on short range, extremely low transmission energy, extremely difficult to intercept, multi-path immunity, low cost (mostly digital architecture), "Moore's Law Radio" (performances, size, data rate, cost follow Moore's Law), simple CMOS transmitter at very low power (Morche, et al. 2006). From its advantages and principles, it seems that IR-UWB solution could be viable in our aircraft context. Concerning weight and power, this solution provides good performances. Indeed, thanks to its simple principle and its mostly digital architecture, the emitter could be very small and light as described in figure 7. Especially, the circuit dimensions will follow the Moore's law, since RF components such as VCO (Voltage Controlled Oscillator), mixer are not used (O'Donnell, et al., 2002).

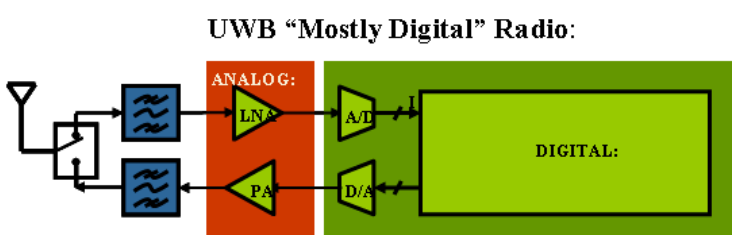

Fig. 7. Illustration of Mostly Digital radio

Moreover, by using very short impulse, the power consumption is reduced in comparison with classical continuous wave techniques (at the same data rate). 


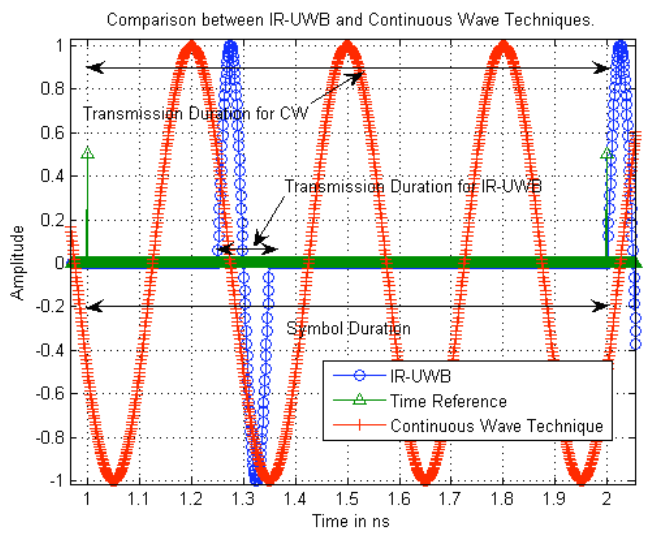

Fig. 8. Duty cycle illustration for IR-UWB and CW techniques.

This figure 8 illustrates the advantage of using pulse in a power constraint context. The duty cycle is defined as the rapport between the transmission duration and the symbol duration. For IR-UWB, duty cycle is the rapport between the pulse duration and the interval between two pulses. Its value will be very lower than 1 . For classical narrow band, the duty cycle has a value of 1 . This low duty cycle is a power consumption advantages for IR-UWB, since during the time of no emission, the emitter will consume less or the emitter could be start a stand by mode. Besides, the regulation of UWB and the low radio range reinforces the good energy comportment of IR-UWB. Furthermore, thanks to the mostly digital architecture, the power consumption will be lesser than in classical techniques because of the absence of VCO, mixer, and others RF components. In addition, the power needs will be decrease according to the Moore's law.

We have studied the behaviour of IR-UWB solution regarding the two main constraint of our context: weight and power. The last need is to be able to achieve the appropriate data rate for each user that is to say about $1 \mathrm{Mbits} / \mathrm{s}$ (this includes audio and commands flow). Now let us study how we could set up the communication and the cohabitation in the confined environment.

\subsection{Dimensioning and Design of Communications System}

Take into account of the large panel of seat layout in aircrafts; we will consider an average case of 300 passengers. Each passenger/seat has two nodes in communications:

- the smart video display unit

- the passenger control unit.

The first statement is that we have to support multiusers links. Indeed we have a total of 600 users in our case study, and the total desired data rate is about $300 \mathrm{Mbit} / \mathrm{s}$ since we have $1 \mathrm{Mbits} / \mathrm{s}$ sending by the display unit to the control unit. For supporting multi user, we proposed to use TimeHopping (TH) (Win, et al., 1998).

\subsubsection{The first solution: Time-Hopping with SDMA}

TH principle is near a dynamic TDMA (Time Division Multiplex Acces). The channel is divided into successive frames (Tf: frame duration), and each frame is divided into Nc time slot (Tc: time slot duration). Each user has a TH-code. This latter defined which time slot should be used for communications of the associated user. An example of $\mathrm{TH}$ concept is exposed on the figure 9.

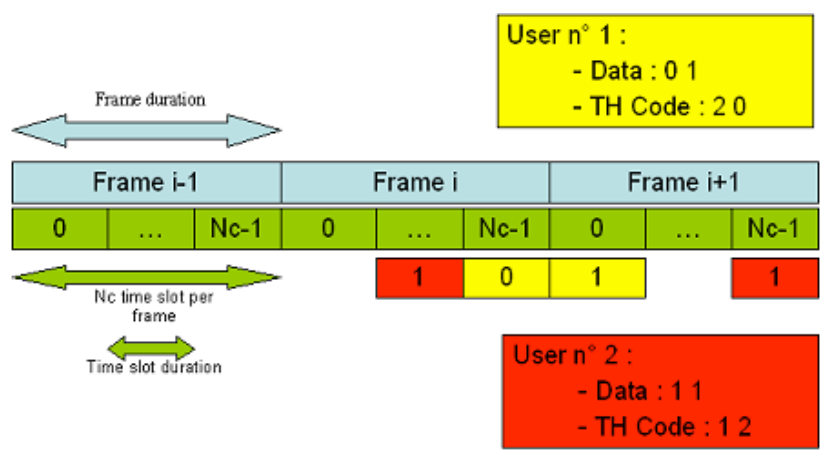

Fig. 9. Illustration of Time-Hopping for a two users link.

We have also to study if the channel in aircraft, for IR-UWB context is able to deal with this numbers (data rate, users ...). We use the UWB IEEE 802.15.4a channel (Molisch, et al. 2004) and its six indoor environments (Industrial LOS/NLOS, Office LOS/NLOS, Residential LOS/NLOS (Line of Sight and Non Line of Sight)) in order to determine the channel capacity. We use these environments because of out lack of channel measurements and modelling in aircraft. The figure 10 proves that a IR-UWB link could support a data rate of $1 \mathrm{Gbits} / \mathrm{s}$ in this indoor environment. We use the BER (Bit Error Rate) versus SNR (Signal to Noise Ratio) in order to compare different solutions performances. We have compared PPM, OOK, and Binary Pulse Amplitude Modulation (BPAM). 

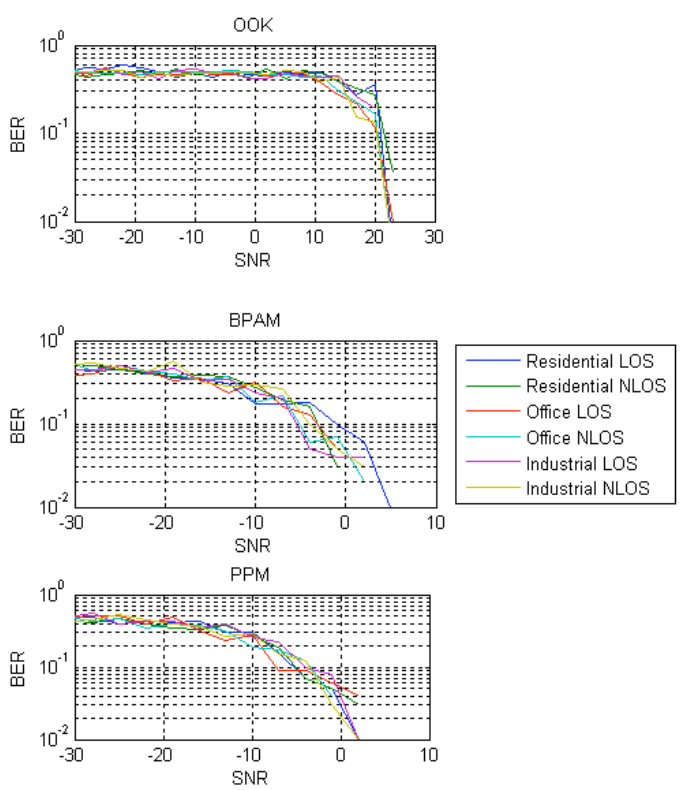

Fig. 10. Bit Error Rate (BER) versus Signal to Noise Ratio (SNR) criteria for OOK, BPAM, PPM comparison in the UWB IEEE 802.15.4a channel indoor environments at $1 \mathrm{Gbits} / \mathrm{s}$.

Figure 10 give us information on the performances of the distinct pulse modulation in different noise level. This information is precious for establishing a link budget and power consumption needs estimation. Besides, figure 10 teach us that a unique system of IR-UWB which cover the whole of the aircraft could be a viable solution (300 Mbits/s (communications needs) is less than 1Gbit/s (channel capacity)).

Nevertheless this solution is not optimal. Indeed, this first solution proposes that all the nodes of the aircraft are including in the same network. But practically, there are not communications between the 600 nodes, only between 2 near nodes (small communications around each seat). The figure 11 illustrates this configuration.

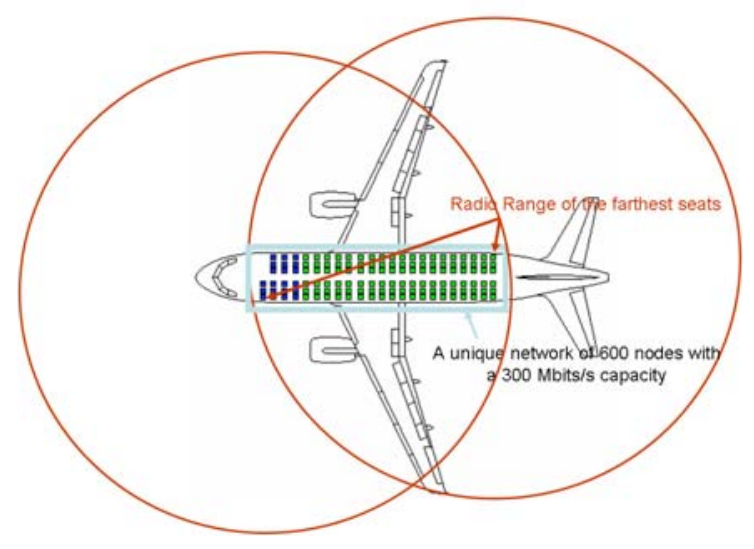

Fig. 11. First solution: only one network with a total radio covers of each node, all nodes are member of the same network.
There are some drawbacks, such as the power consideration, interference. Using only one network implies a bigger energy consumption for enabling the radio cover by means of omni-directional antennas, since two nodes located at each end of the aircraft should communicate. The bigger the distance is, the more important the power required is. Concerning interference, with this unique networks solution, we have to deal with the concurrent access for 600 nodes for only one radio channel. Two group of communicating nodes have to share the media capacity whereas there won't have to communicate each other. In others words, here, we share the capacity of the channel between 600 nodes, whereas you could share the channel capacity between only communications nodes (2 nodes).

3.3.2 The second solution: Time-Hopping with SDMA.

We propose to set up, thanks to SDMA (Spatial Division Multiplex Access) 300 networks of two nodes instead of 1 network of 600 nodes.

For implementing SDMA, we will make two actions:

- $\quad$ power control (Alabeedi, 2005)

- $\quad$ set up directional or smart antennas (Nasipuri, et al. 2002).

The first one will permit to reduce the radio range and consequently will define a large number of networks as illustrated in figure 12.
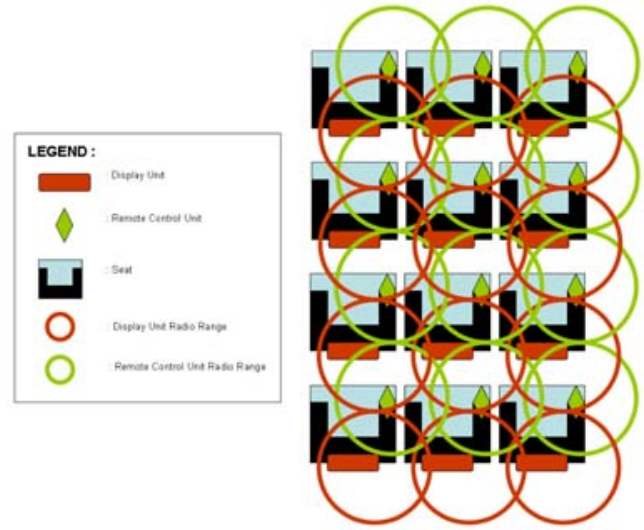

Fig. 12. One network by remote control unit and display unit couple with omni-directional antennas.

Figure 12 exposes the creation of different networks, limited by their radio range and including only communications related nodes. Indeed, it is useless to include in the same radio range two nodes which won't communicate each others. Thus with this first measure, we have reduce the power consumption since we have reduce the radio range of each nodes as illustrated in table I. 
$\underline{\text { Table I - Link budget comparison for our two }}$ solutions (TH alone versus TH+SDMA) in residential LOS UWB IEEE 802.15.4a channel.

\begin{tabular}{|l|c|c|c|}
\hline Solution & Only one network & Multi 2-nodes networks & Unité \\
\hline Distance & 40 & 0,5 & $\mathrm{~m}$ \\
\hline Bit Rate & 0,4 & 0,001 & $\mathrm{Gbits} / \mathrm{s}$ \\
\hline Tx Power & 0 & 0 & $\mathrm{dBm}$ \\
\hline Tx antenna Gain & 0 & 0 & $\mathrm{dBi}$ \\
\hline Rx Antenna gain & 0 & 0 & $\mathrm{~dB}$ \\
\hline High Frequency & 5,15 & 5,15 & $\mathrm{GHz}$ \\
\hline Low Frequency & 10,6 & 10,6 & $\mathrm{GHz}$ \\
\hline Margin & 0 & 0 & $\mathrm{~dB}$ \\
\hline Center Frequency & 7,875 & 7,875 & $\mathrm{GHz}$ \\
\hline Wavelength & 5,038095238 & 0,038095238 & $\mathrm{~m}$ \\
\hline Central Frequency (fc) & 1 & 5 & $\mathrm{GHz}$ \\
\hline Distance reference (do) & 43,9 & 1 & $\mathrm{~m}$ \\
\hline Patlowww at 1m (Plo) & 1,79 & 43,9 & $\mathrm{~dB}$ \\
\hline Pathloss Exponent (n) & 2,22 & 1,79 & \\
\hline Shadowing (S) & 1,12 & 2,22 & $\mathrm{~dB}$ \\
\hline Frequency Dependance (k) & 3 & 1,12 & \\
\hline Antenna Loss & 30,0064161 & 45,94110533 & $\mathrm{~dB}$ \\
\hline Pathloss (IEE 802.15.4a) & $1,38 \mathrm{E}-23$ & $1,38 \mathrm{E}-23$ & $\mathrm{~dB}$ \\
\hline Boltzmann Constant & 300 & 300 & $\mathrm{~K}$ \\
\hline Temperature & 37,80 & 97,89 & $\mathrm{~dB}$ \\
\hline Eb/No & & & \\
\hline
\end{tabular}

Table I mention the available $\mathrm{Eb} / \mathrm{No}$ at the receiver for our two configurations. The first one is TimeHopping for all nodes located in aircraft (40m). While the second one solution uses TH and SDMA in a lot of 2-nodes network on very small area (seat passenger area $(50 \mathrm{~cm}))$. Available Eb/No, calculated by table I, could be used as a power constraint criterion to establish a classification between or two solutions. In our study case, $\mathrm{Eb} / \mathrm{No}$ is higher for the TH-SDMA solution, as a result, for obtaining a wanted $\mathrm{Eb} / \mathrm{No}$ this solution will need lesser Tx power than TH solution. Table II illustrate this statement by exposing the needed Tx power in order to achieve a wanted Eb/No.

Table II - Power constraint comparison according the "Tx power required" criteria for achieved a desired $\mathrm{Eb} / \mathrm{No}$, in residential LOS UWB IEEE 802.15.4a channel.

\begin{tabular}{|l|c|c|c|}
\hline Solution & Only one network & Multi 2-nodes networks & Unité \\
\hline Distance & 40 & 0,5 & $\mathrm{~m}$ \\
\hline Bit Rate & 0,4 & 0,001 & $\mathrm{bbits} / \mathrm{s}$ \\
\hline Tx antenna Gain & 0 & 0 & $\mathrm{dBi}$ \\
\hline Rx Antenna gain & 0 & 0 & $\mathrm{~dB}$ \\
\hline High Frequency & 5,15 & 5,15 & $\mathrm{GHz}$ \\
\hline Low Frequency & 10,6 & 10,6 & $\mathrm{GHz}$ \\
\hline Margin & 3 & 3 & $\mathrm{~dB}$ \\
\hline Pathloss (IEEE 802.15.4a) & 80,0064161 & 45,94110533 & $\mathrm{~dB}$ \\
\hline Boltzmann Constant & $1,38 \mathrm{E}-23$ & $1,38 \mathrm{E}-23$ & $\mathrm{~J} / \mathrm{K}$ \\
\hline Temperature & 300 & 300 & $\mathrm{~K}$ \\
\hline Wanted Eb/No & 10 & 10 & $\mathrm{~dB}$ \\
\hline Tx Power Required & $-27,80$ & $-87,89$ & $\mathrm{~dB}$ \\
\hline
\end{tabular}

Table II proves that, according the power criterion (and autonomy) our second solution is better, since the required Tx power is very lower than in first solution case.

Nevertheless, since radio range is defined approximately as a sphere around the transmitter nodes we couldn't separate precisely networks (in the second solution). There is obligatory some areas where two networks will be in concurrence. We called this, inter UWB user interference (IU²I), and it is illustrated in the figure 9 where circles are overlapped each other. On this latter we can see easily that different radio ranges are overlapped.
Thus the access to the medium should be share between a few numbers of seats. For combating $\mathrm{IU}^{2} \mathrm{I}$ we propose to use directional or smart antenna (Kardo - Sysoev, 2003).

A directional antenna is an antenna which radiates greater power in one or more directions allowing for increased performance on transmit and receive and reduced interference from unwanted sources. Thus we suppress the spherical radio range and associated interferences; instead of it we have LOS communications. By using power control and directional antenna, we decrease the interference inter user since the volumes used by radio signals are disjoined and lesser than in omni-directional antennas case. Indeed, interferences exist only when two beams of a Tx and a Rx directional antennas are aligned and in the power radio range. Thus if we correctly arrange the antenna of the display unit to only radiate on the control unit of the associated seat, we could assure the cohabitation of the 300 networks of two nodes in the aircraft without interferences. The interference inter networks are decreased thanks to SDMA (power control and directional antenna) while inter user in networks are suppressed by the use of TimeHopping. In addition, using discontinuous emission and $\mathrm{TH}$ which randomize the signal is also a warranty of interference decrease. Figure 13 illustrates this second solution.
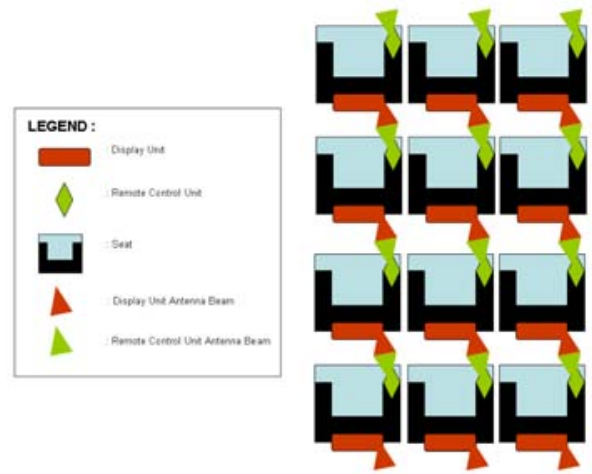

Fig. 13. Illustration of our second solution: directive antenna and two nodes per network.

With this second solution we have designed the communication system which is able to support the entertainment communications for each passenger. We have also to consider interference with other radio system in the aircraft such as WiFi for example. Our solution based on IR-UWB will not interfere a lot of with others radio system thanks to the weakness of Tx power as indicated in the table II.

\section{AN AD HOC AND SELF-ORGANIZED NETWORK.}


There are additional constraints on our networks. Each remote control is mobile thanks to a little wire which interconnect it with the passenger control unit. They could also be changed if they don't operate correctly. That is to say, if a remote control is damaged, for the next flight it will be replaced by a new one, and this latter has to be operational without any parameterization. Thus the network must be self organized. This implies a need of protocol for allow self organized capacity and the reduced-mobility of the remote control node.

The problem is to determine the network membership of the mobile control unit. Indeed, we mustn't authorize communication between the control unit of one seat and the display unit of another seat at the exception of the in front of seat. Our proposition is to, at the beginning, define the network and the associated nodes: two nodes by networks, one display unit and one control unit. Possible criteria; in concurrent case: two remote units in the radio range of a display unit; is the distance from the display unit. The shorter the distance is, the higher the probability of being the appropriate remote unit is. We could consider that at the beginning of the network formation step, the space is swept by the distinct antenna in order to detect the presence of nodes. The figure 14 illustrates a network formation problem.
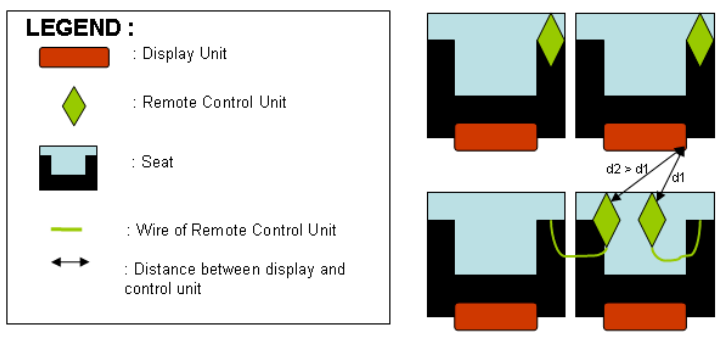

Fig. 14. Determination of network composition thanks to distance information.

This proposition could benefit from the use of IRUWB and its good behaviour for localization (Gezici, et al. 2005). Indeed, thanks to the very small duration of UWB impulse, the localization is simpler and better precise than in classical narrow band technique. The classical and very simple ToA (Time of Arrival (Gezici, et al. 2005)) algorithm is set up. ToA's concept is to determine the time of arrival of the received pulse for obtaining the time of flight and thus, the distance between emitter and receiver. (Note that the propagation speed of pulse is known). ToA algorithm is set through a matched filter in our system. Thanks to ToA the receiver is able to determine its distance, called 'd', between it and the emitter. With this distance information, receiver is able to place the emitter estimate position on a sphere of distance information radius ('d') (Figure 15)

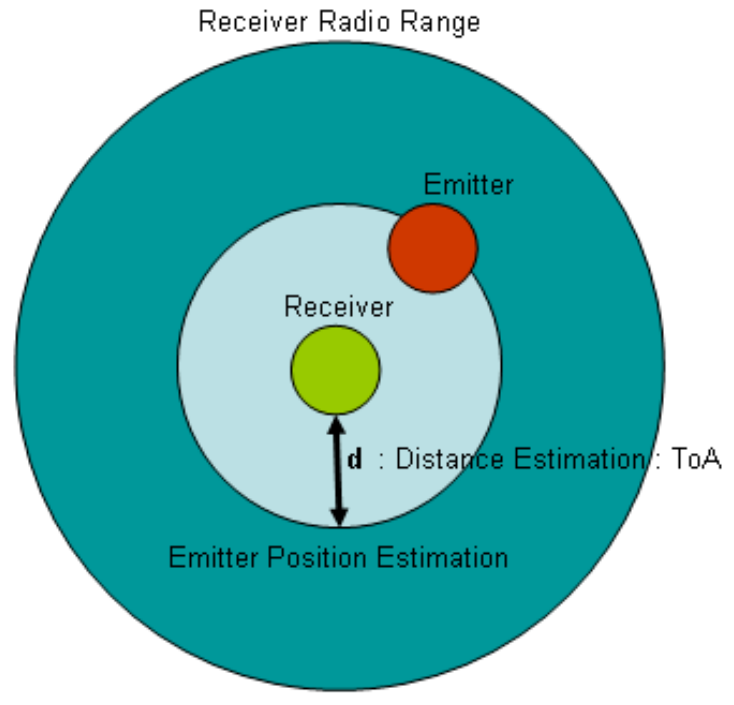

Fig. 15. Distance and position estimation of the emitter by the receiver thanks to ToA in omnidirectionnal antenna case.

Thanks to directional antenna we could select only a conical part of the sphere (Figure 16). Thus the localization is more precise. Nevertheless the precision depends also on the beam width of the antenna (in addition to ToA precision parameters: pulse duration, algorithm implementation, clock frequency).

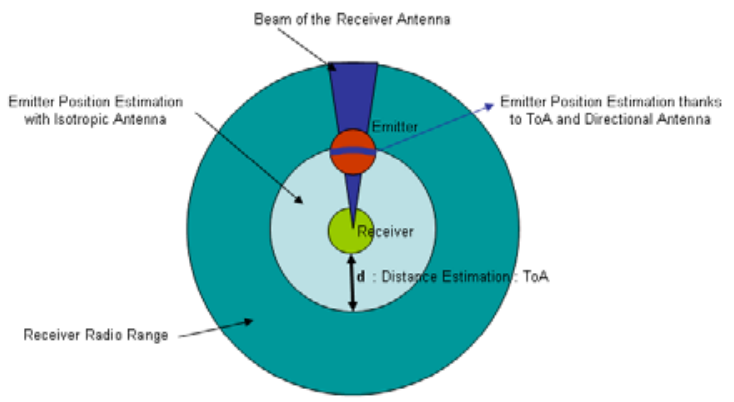

Fig. 16. Precision improvement in position estimation thanks to directional antenna.

Once we have determined the composition of each network, we could attribute an identifier for enabling only the communication between these two nodes. This further protection permit to deal with the case of a non appropriate remote unit is in the radio range of a non appropriate screen (figure 17).
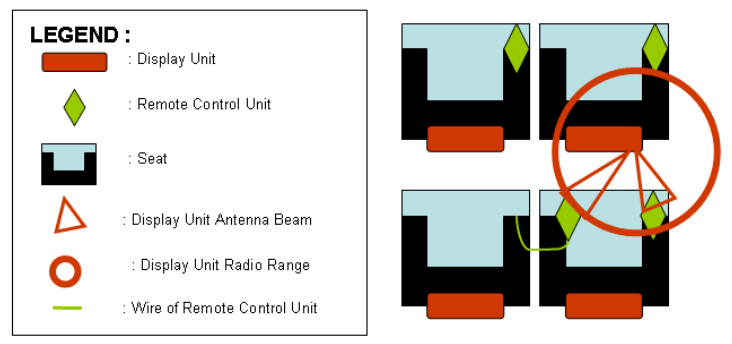
Fig. 17. Illustration of the case of 3 nodes in the PHY layer network.

Figure 17 expose the case of the presence of three nodes in the PHY layer network but thanks to the identifier there are only two nodes in the logic networks. Identifier could be defined with a common part as network identifier and a part as node identifier. Communications are only permit for common network identifier node. And identifier node par could choose randomly.

\section{CONCLUSION}

In this paper we have proposed, designed and dimensioned a communication system for aircraft entertainment network. In a first time we have exposed the specificities of such context and then we have proposed a solution. The primordial constraints are weight, power, interference, ad hoc network, self-organized network and the support of 100-300 nodes.

Our solution is based on IR-UWB with TimeHopping and SDMA. This latter use power control and directive antenna for share the medium and reduce interference. We use also localization in order to deal with network formation problematic to respond to the mobility and self-organized network constraint.

Our proposition consists in dividing a large nodes high data rate network in a large number of 2-nodes low data rate networks thanks to directive antenna, and power control (SDMA). By means of this concept we have to deal with the coexistence problematic due to high density networks by square meters. This problem is interference problem.

Time-Hopping IR-UWB with SDMA is the best wireless solution for this context because of its behaviour regarding simplicity, dimensions, cost and power constraints.

\section{REFERENCES}

T. W. Barret, "History of UltraWideBand (UWB) radar \& communications: pioneers and inventors", Progress in Electromagnetics Symposium 2000, Cambridge, MA, July 2000

A. F. Kardo - Sysoev, "Generation and Radiation of UWB - signals", $33^{\text {rd }}$ European Microwave Conference - Munich 2003

Saad Alabeedi (2005), Antenna Beamforming for ad hoc networks, course of Carleton University

S. Gezici, Z. Tian, G.B. Giannakis, H. Kobayashi, A.F. Molisch, H.V. Poor, Z. Sahinoglu (2005),
Localization via ultra wideband radios, IEEE Signal Processing Magazine.

A. Molisch, K. Balakrishnan, C. Chong, S. Emani, A. Fort, J. Karedal, H. Schantz, U. Schuster, K. Siwiak (2004), IEEE 802.15.4a channel model - final report, IEEE 802.15.4a sub-group modelling.

D. Morche, C. Dehos, T. Hameau, D. Larchartre, M. Pelissier, D. Helal, L. Smaini (2006), Vue d'ensemble des architectures RF pour l'UWB, LETI, Ecole ULB de Valence à l'ESISAR.

A. Nasipuri, K. Li and U. R. Sappidi (2002), Power Consumption and Throughput in Mobile Ad Hoc Networks using Directional Antennas, Computer Communications and Networks, IEEE.

Ian O'Donnell, Mike Chen, Stanley Wang, Bob Brodersen (2002), An Integrated, Low-Power, Ultra-Wideband Transceiver Architecture for Low-Rate Indoor Wireless Systems, Berkeley Wireless Research Center, Univ. of California, Berkeley, EEE CAS Workshop on Wireless Communications and Networking, Pasadena

I. Opperman, Jari Iinatti, Matti Hčamčalčainen (2004), UWB theory and applications, Wiley.

M.Z. Win, R.A. Scholtz (1998), Impulse radio: how it works, IEEE Communications Letters, vol. 2, no. 2. 